\title{
Wisdom Tooth Surgery Complications-Local Anaesthesia versus General Anaesthesia
}

\author{
Hui Woon Lim¹, Nur Izzati Mahmod', Fathinah Hanem Azam Zaki', Fo Yew Tan1, \\ Sathesh Balasundram¹, Tassha Hilda Adnan² \\ ${ }^{1}$ Department of Oral Surgery, Sultanah Nora Ismail Batu Pahat Hospital, Ministry of Health, Batu Pahat, Malaysia \\ ${ }^{2}$ Clinical Research Centre, Kuala Lumpur Hospital, Ministry of Health, Kuala Lumpur, Malaysia \\ Email: izati_mahmod@yahoo.com
}

How to cite this paper: Lim, H.W., Mahmod, N.I., Zaki, F.H.A., Tan, F.Y., Balasundram, S. and Adnan, T.H. (2019) Wisdom Tooth Surgery Complications-Local Anaesthesia versus General Anaesthesia. Open Journal of Stomatology, 9, 51-63. https://doi.org/10.4236/ojst.2019.93006

Received: January 10, 2019

Accepted: March 11, 2019

Published: March 14, 2019

Copyright ( 2019 by author(s) and Scientific Research Publishing Inc. This work is licensed under the Creative Commons Attribution International License (CC BY 4.0).

http://creativecommons.org/licenses/by/4.0/

\section{(c) (i) Open Access}

\begin{abstract}
Purpose: To compare the complication rates arising from surgical removal of lower third molars (L3M) under general anaesthesia (GA) versus local anaesthesia (LA) in the Oral and Maxillofacial Surgery (OMFS) Department, Hospital Sultanah Nora Ismail (HSNI), Batu Pahat, Johor, Malaysia. Materials and methods: This is a retrospective clinical audit of patients who underwent L3M removal under LA or GA from $1 / 1 / 2013$ to 31/3/2018, with recorded complications such as surgical site infection (SSI), wound breakdown, severe pain, trismus, retained tooth structure, nerve injury and dry socket evaluated at different time intervals. Results: A total of 313 patients with 375 L3M were included in this study (male: 160, 51.1\%; female: 153, 48.9\%) with an age range of 18 to 40 years (mean $=27.43$ years). $79 \mathrm{~L} 3 \mathrm{M}$ were removed under GA (34.2\% were classified as mild; $65.8 \%$ were moderate), whereas $296 \mathrm{~L} 3 \mathrm{M}$ were removed under LA, (31.4\% were mild impaction, $63.9 \%$ moderate and $4.7 \%$ severe. Preoperative antibiotics were given before all L3M removal under GA, while only 23 out of 296 L3M removal under LA had antibiotics. $15.2 \%$ of L3M removal under GA and $16.6 \%$ of those done under LA were associated with complications. Generally, patient with GA had lesser complications; however only SSI outcome was significant $(\mathrm{p}=0.034)$. Conclusion: L3M removal under LA may have a higher risk of SSI when compared to GA. This raises the possibility that a single prophylactic antibiotic dose may prevent SSI in LA procedures.
\end{abstract}

\section{Keywords}

Lower Third Molar, Complication, Local Anaesthesia, General Anaesthesia

\section{Introduction}

Minor oral surgery (MOS) for removal of impacted third molar (3M) is a com- 
mon procedure carried out in oral surgery units. Lower third molar (L3M) can be carried out under local anaesthesia (LA) or general anaesthesia (GA). It is not uncommon to have multiple L3M removed under GA in centres with general anaesthesia facilities.

Bouloux et al. (2007) [1] reported that the incidence for surgical site infection (SSI) in $3 \mathrm{M}$ removal was $1 \%-4 \%$. It is uncommon to have nerve injury after L3M removal, but if it happens, it will be one of the most undesirable complications and can be distressing to certain patients [2].

The incidence for temporary nerve injury ranges from $0.5 \%$ - 8\% [3] [4] [5], while permanent injury incidence has been reported at 1\% [5] [6].

As for alveolar osteitis, the incidence shown in published studies ranges form $0.3 \%-26 \%$ [3] [7] [8] [9] [10]. Mandibular fracture and osteomyelitis were considered as rare complications during L3M removal [11]. The reported incidence for mandibular fracture was $0.0049 \%$ [12]. These published complication rates are vital in monitoring the surgical risks in patients and there is a growing need to regularly audit such procedures.

The Oral and Maxillofacial Surgery (OMFS) department in Hospital Sultanah Nora Ismail Batu Pahat (HSNI) has been carrying out minor oral surgery (MOS) procedures for many years since its setting up in 2012. While the complications (SSI and nerve injuries) are monitored, we have not been able to compare the complication rates for these procedures when conducted under LA and GA.

The aim of the current study is to assess the rate of complication of L3M removal under GA and LA in this centre.

\section{Methods}

This is a retrospective study of L3M removal under LA or GA performed at the Department of OMFS, HSNI. L3M were removed by specialists or senior dental officers. The patients' details were collected from the operating theatre list, surgical notes and clinical records. A variety of data were collected for each patient including age, sex, medical status at the time of procedure and the type of procedure performed.

Inclusion criteria:

1) Patients from the age of 18 to 40 years old.

2) Patients who had undergone MOS of L3M in HSNI (single or multiple teeth).

3) Patients treated within the duration from 01/01/2013-31/3/2018.

Exclusion Criteria:

1) Medically compromised patients (e.g. diabetes mellitus, immune-compromised).

2) Dental clearance cases.

3) Trauma patients whose L $3 M$ was removed during surgical intervention for the traumatic injury (for example L3M removal during open reduction and internal fixation procedure of mandibular fracture). 
4) Acute abscess patients whose removal was done as an "emergency" procedure.

5) Removal of residual L3M cases such as residual tooth structure that had prior attempted removal.

Procedure:

All L3M removal under LA or GA and meeting the criteria of this study were identified:

1) All clinical notes and patient records (radiographs) were retrieved and assessed.

2) Pre operative and post operative assessment data was collected and collated.

3) Follow-up intervals were recorded and analyzed accordingly.

Patients were given treatment options for MOS either to be done under LA or GA, if bilateral L3M indicated for removal, patient were advised for the procedure to be done under GA for the sake of patient comfort and convenience. For complicated cases of L3M such as severe impaction or patients that have poor tolerance to pain, GA was suggested. Apart from that, for patients who are anxious, high gag reflex, contraindication to LA/ineffective LA, were also suggested for GA procedure.

The MOS procedure of L3M under LA was done with an inferior alveolar nerve (IAN) block and long buccal nerve block (2\% Mepivacaine with 1:100,000 epinephrine) [13] in a sterile setting. A full thickness mucoperiosteum flap was raised, bone guttering and tooth sectioning were done accordingly under copious irrigation with sterile saline solution. Flap was re-approximated with sutures. Post op instruction and medication was given (analgesic and mouthwash). Tablet prednisolone $10 \mathrm{mg}$ was prescribed post operatively for 3 days.

Meanwhile, MOS of L3M under GA involves the same procedure and surgical technique as LA, post op instruction and medication were given (analgesic and mouthwash) prior to discharge. For GA procedure, patient was admitted one day prior. On the day of surgery, patient was orally intubated, sedated and scrubbed. IV Dexamethasone $8 \mathrm{mg}$ and antibiotics were served as pre-operative medication for GA procedure given by anaesthesist after intubation [14].

Data to be collected

1) Patients' demographic details.

2) L3M details-diagnosis, site, proximity with inferior alveolar nerve (IAN), type of tooth impaction based on Freudlsperger et al. [15] as presented in Table 1.

3) Surgery details-surgical approach, date of MOS, date of discharge, intra operative complication, post operative complications.

4) Details of pre and postoperative and medication-antibiotics details.

5) Complications.

a) SSI;

b) Wound dehiscence;

c) Severe pain with pain score $\geq 6$;

d) Trismus $<2 \mathrm{~cm}$ persisting beyond day 3 post op;

e) IAN injury;

f) Dry socket; 
Table 1. Score for difficulty of surgical removal L3M based on radiographic position.

\begin{tabular}{|c|c|}
\hline Anatomical position & Score \\
\hline \multicolumn{2}{|l|}{ Angulation (inclination of longitudinal axis): } \\
\hline Mesioangular & 1 \\
\hline Horizontal/transverse & 2 \\
\hline Impacted vertical & 3 \\
\hline Distoangular & 4 \\
\hline \multicolumn{2}{|l|}{ Depth of impaction (with respect to occlusal plane): } \\
\hline Occlusal plane of impacted tooth at same level as occlusal plane of second molar & 1 \\
\hline Occlusal plane of impacted tooth between occlusal plane and cervical line of second molar & 2 \\
\hline Impacted tooth below cervical line of second molar & 3 \\
\hline \multicolumn{2}{|l|}{ Available space (with respect to ascending mandibular ramus): } \\
\hline $\begin{array}{l}\text { Sufficient space between ramus and distal part of second molar to accommodate } \\
\text { mesiodistal diameter of third molar }\end{array}$ & 1 \\
\hline $\begin{array}{l}\text { Space between second molar and ramus of mandible is less than mesiodistal diameter of } \\
\text { third molar }\end{array}$ & 2 \\
\hline All or most of third molar is in ramus of mandible & 3 \\
\hline
\end{tabular}

Score: $3-4=$ mild; $5-7=$ moderate; $8-10=$ severe.

g) Retained root.

6) Complication onset period was categorized in our center as follows:

a) Immediate-from the time of MOS till day 6 post-operatively;

b) Intermediate-from 1 week to 6 weeks post-operatively;

c) Late-after 6 weeks post-operatively.

Data handling and record keeping

Data was collected from the patients' notes in accordance and adherence to Data Protection Act 1998 and Caldicott and analysed using IBM SPSS Statistics 20 (IBM SPSS Statistics for Windows, IBM Corp, Armonk, NY). The continuous data was expressed as mean and standard deviation (SD), while categorical data was described in the form of frequency and its percentage. Differences and association in the patient's demographic profiles, clinical characteristics, and the complication following wisdom tooth surgery between groups of general anaesthesia (GA) and local anaesthesia (LA) were assessed using independent t-test for continuous variables; and Pearson chi-square or Fisher's exact test for categorical variables. Odds ratios (OR) and $95 \%$ confidence intervals (CI) were calculated using logistic regression, to determine the association between the type of anaesthesia with each type of complication. All p-values reported were two sided, and a p-value of less than 0.05 was considered significant.

\section{Results}

313 patients were included in this study (male: $160,51.1 \%$; female: $153,48.9 \%$ ) with an age range of 18 to 40 years (mean $=27.43$ years) in Table 2 . A total of $375 \mathrm{~L} 3 \mathrm{M}$ was removed $(\mathrm{GA}=79 ; \mathrm{LA}=296)$. 
Table 2. Characteristics of patients $(n=313)$.

\begin{tabular}{|c|c|c|c|c|}
\hline & \multirow{2}{*}{$\begin{array}{c}\text { All } \\
(\mathrm{N}=313) \\
\mathrm{n}(\%)\end{array}$} & \multicolumn{2}{|c|}{ Procedure } & \multirow[b]{2}{*}{$\mathrm{p}$-value } \\
\hline & & $\begin{array}{l}\text { General anaesthesia } \\
\quad(\mathrm{n}=41), \mathrm{n}(\%)\end{array}$ & $\begin{array}{l}\text { Local anaesthesia } \\
(\mathrm{n}=272), \mathrm{n}(\%)\end{array}$ & \\
\hline \multicolumn{5}{|l|}{ Age at surgery; years: } \\
\hline Mean (SD) & $27.43(5.01)$ & $25.07(4.18)$ & $27.78(5.03)$ & $0.001^{\mathrm{a}}$ \\
\hline Range & 18,40 & 18,35 & 18,40 & \\
\hline \multicolumn{5}{|l|}{ Gender: } \\
\hline Male & $160(51.1)$ & $19(46.3)$ & $141(51.8)$ & $0.431^{\mathrm{b}}$ \\
\hline Female & $153(48.9)$ & $22(53.7)$ & $131(48.2)$ & \\
\hline \multicolumn{5}{|l|}{ Ethnic: } \\
\hline Malay & $232(74.1)$ & $31(75.6)$ & $201(73.9)$ & $0.893^{c}$ \\
\hline Chinese & $73(23.3)$ & $10(24.4)$ & $63(23.2)$ & \\
\hline Indian & $7(2.2)$ & $0(0.0)$ & $7(2.6)$ & \\
\hline Others & $1(0.3)$ & $0(0.0)$ & $1(0.4)$ & \\
\hline \multicolumn{5}{|l|}{ No. of tooth removal: } \\
\hline Single & $251(80.2)$ & $3(7.3)$ & $248(91.2)$ & $<0.001^{\mathrm{b}}$ \\
\hline Multiple & $62(19.8)$ & $38(92.7)$ & $24(8.8)$ & \\
\hline
\end{tabular}

$\mathrm{SD}=$ Standard deviation; Range is reported as minimum, maximum value. ${ }^{\mathrm{a}}$ Independent $\mathrm{t}$-test; ${ }^{\mathrm{b}} \mathrm{Chi}$-square test; 'Fisher's exact test.

Table 3 shows from the 79 L3M that were removed under GA, 34.2\% were classified as mild and $65.8 \%$ were moderate, whereas from the $296 \mathrm{~L} 3 \mathrm{M}$ which were removed under LA, the degree of impaction was mild: $31.4 \%$; moderate: $63.9 \%$; severe: $4.7 \%$. $26.6 \%$ of L3M in GA patients had close proximity to IAN while $21.3 \%$ of L3M in LA patients was close to nerve. All L3M patients in GA procedures were given preoperative antibiotics while $23 \mathrm{~L} 3 \mathrm{M}$ patients in LA procedure were prescribed with antibiotics.

The complication rate was $15.2 \%$ and $16.6 \%$ for GA and LA respectively. Intra-operative complications were present in both GA and LA procedure at 3.8\% and $1.4 \%$ respectively as shown in Table 3. Only SSI showed significant difference when comparing LA and GA procedure at $\mathrm{p}$ value $=0.034$ in multivariable analysis (adjusted OR: 4.51,95\% CI: 1.12, 18.2) as described in Table 4. Nerve injury and dry socket were the highest occurring complications in our results for both LA and GA procedures. Retained tooth structure was the least prevalent complication in our study (4.1\% in LA). Severe pain was also one of the complications recorded in our study ( $8.3 \%$ for LA; $14.3 \%$ for GA). Only $6.1 \%$ of teeth in LA procedure had wound breakdown complication. For severe swelling and trismus, it was found to be $16.7 \%$ in LA and $2 \%$ in GA.

Table 5 shows $50 \%$ of cases were noted to have complications in both immediate and intermediate period for GA procedure ( $\mathrm{n}=6 \mathrm{each}$ ). A higher complication rate (85.7\%) was found in LA procedures during immediate interval while 
Table 3. The association of variables with the anaesthesia procedures, by treatment $(\mathrm{n}=$ 375).

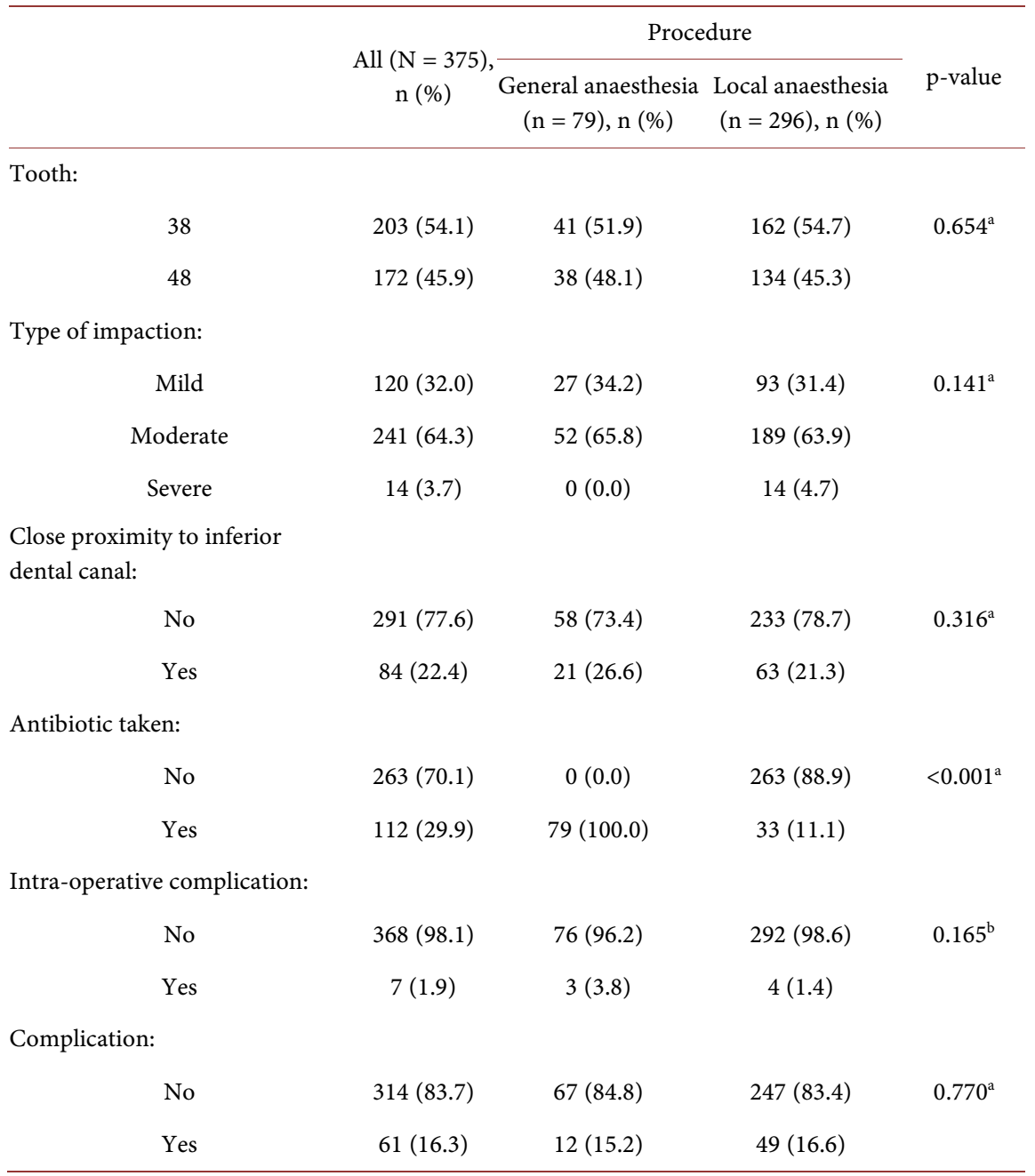

${ }^{\mathrm{a}}$ Chi-square test; ${ }^{\mathrm{b}}$ Fisher's exact test.

Table 4. The association of general and local anaesthesia with each type of complication, using logistic regression.

\begin{tabular}{|c|c|c|c|c|}
\hline & \multicolumn{2}{|c|}{ Type of complication } & \multicolumn{2}{|c|}{ Multivariable analysis* } \\
\hline & n (\%) & n (\%) & Adj. OR (95\% CI) & p-value \\
\hline Overall complication & No & Yes & & \\
\hline \multicolumn{5}{|l|}{ Procedure: } \\
\hline GA & $67(84.8)$ & $12(15.2)$ & 1.00 & 0.013 \\
\hline \multirow[t]{2}{*}{ LA } & $247(83.4)$ & $49(16.6)$ & $3.67(1.32,10.21)$ & \\
\hline & No SSI & SSI & & \\
\hline \multicolumn{5}{|l|}{ Procedure: } \\
\hline GA & $74(93.7)$ & $5(6.3)$ & 1.00 & 0.034 \\
\hline \multirow[t]{2}{*}{ LA } & $285(96.3)$ & $11(3.7)$ & $4.51(1.12,18.20)$ & \\
\hline & No severe pain & Severe pain & & \\
\hline
\end{tabular}




\section{Continued}

Procedure:

GA

78 (98.7)

1 (1.3)

1.00

0.259

LA

289 (97.6)

$7(2.4)$

$4.40(0.34,57.61)$

No nerve injury Nerve injury

Procedure:

GA

$74(93.7)$

5 (6.3)

1.00

0.701

LA

No dry socket

$13(4.4)$

$1.38(0.27,7.11)$

Procedure:

GA

75 (94.9)

$4(5.1)$

1.00

0.849

LA

$279(94.3)$

$17(5.7)$

$1.19(0.19,7.37)$

Adj. $\mathrm{OR}=$ Adjusted odds ratio; $\mathrm{CI}=$ Confidence interval. Complication "Yes" is coded as the event of interest; percentages is reported by row (by each procedure). The other type of complication is not available since there is " 0 " or very small cell observation. *Adjusted for age, gender, ethnic, tooth, type of impaction, close proximity to ID canal, antibiotic taken and intra-operative complication.

Table 5. Distribution of type and complication interval between the 2 procedures among patient with complication $(n=61)$.

\begin{tabular}{cccc}
$\begin{array}{c}\text { General anaesthesia } \\
(\mathrm{n}=12)\end{array}$ & $\begin{array}{c}\text { Local anaesthesia } \\
(\mathrm{n}=49)\end{array}$ & p-value \\
\hline $\mathrm{n}$ & $(\%)$ & $\mathrm{n}$ & $(\%)$
\end{tabular}

Complication interval period:

$\begin{array}{llllll}\text { Immediate (within week 1) } & 6 & (50.0) & 42 & (85.7) & 0.014 \\ \text { Intermediate (between week 1 - 6) } & 6 & (50.0) & 7 & (14.3) & \end{array}$

Type of complication*:

$\begin{array}{lccccc}\text { Surgical site infection } & 5 & (41.7) & 11 & (22.4) & 0.270 \\ \text { Wound breakdown } & 0 & (0.0) & 3 & (6.1) & >0.995 \\ \text { Severe pain } & 1 & (8.3) & 7 & (14.3) & >0.995 \\ \text { Severe swelling and trismus } & 2 & (16.7) & 1 & (2.0) & 0.096 \\ \text { Retained tooth structure } & 0 & (0.0) & 2 & (4.1) & >0.995 \\ \text { Nerve injury } & 5 & (41.7) & 13 & (26.5) & 0.313 \\ \text { Alveolar osteitis (dry socket) } & 4 & (33.3) & 17 & (34.7) & >0.995\end{array}$

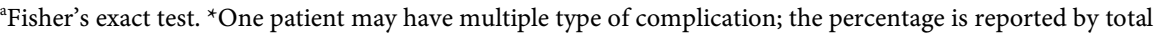
cases by each procedure.

only $14.3 \%$ presented with complication during intermediate period. Both GA and LA procedure were not recorded to have complications at late interval.

\section{Discussion}

MOS of L3M is a common procedure and complications that arise should be managed accordingly. We aimed to assess the rate of complication post MOS 
and to identify possible areas of improvement.

SSI in L3M procedure can be characterised by swelling or fluctuation and purulent discharge from the socket with associated pain [16]. The risk factors identified as being associated with this complication are longer surgical procedure, severity of impaction, age of patient above 25 years old, sterility of working environment and preoperative antibiotic used in GA procedure. Bouloux et al. (2007) [1] reported that the incidence for SSI in $3 \mathrm{M}$ removal is $1 \%-4 \%$. This correlates with our study finding (3.7\% for LA and $6.3 \%$ for GA). Clauser et al. (2009) [17] showed that an age of above 25 years old poses a high risk of postoperative infection rate. Our study shows that most of the patients that had SSI in LA procedure were more than 25 years old. Bruce et al. (1980) [7] claimed that as the patients get older, the extractions were more difficult because of increasing bone sclerosis and thinning of the periodontal ligament hence longer operating time was needed and subsequently increasing the possibility of a postoperative infection. Benediktsdóttir et al. (2004) [8] in a prospective study of 388 lower third molars (M3s), showed a 2.8\% infection rate, with full bony impactions being more frequent and the odds ratio of infection increasing from 1.99 in patients aged 18 to 24.5 years to 5.39 in those aged over 24.5 years. The outcome of our cases in moderate and severe type of impaction which were done under LA supports this finding.

Sisk et al. (1986) [3] showed in their prospective study of 708 patients with impacted third molars removals, the complication rate, including infections, rose with increasing surgical time, although the overall infection rate was only $0.89 \%$. As compared to GA procedure, duration of MOS in LA procedures is longer as patient cooperativeness needs to be taken into consideration. For LA procedures, longer duration is expected as patients might experience discomfort intra-operatively and attention must be given, thus increasing the duration of surgical time and prolonged open wound exposure. This inadvertently poses a higher risk to develop SSI. SSI was recognized as a significant contributor to expense, morbidity and mortality within the health care system. Hence, identifying the variables that affect the incidence of SSI was a crucial step to help reduce the incidence and expense of SSI [18].

When comparing LA and GA environment, performing procedure under GA environment was more sterile as a positive pressure gradient and air filters between the theatre environment and its surroundings can reduce airborne pathogens and contamination. Conventional (turbulent) ventilation changes the air 20 times per hour. Temperature was maintained between $18^{\circ} \mathrm{C}-25^{\circ} \mathrm{C}$ while humidity was maintained at $40 \%-60 \%$ [19]. Hence GA procedures can reduce the risk of SSI. In almost all the SSI cases, the treatment of choice involves systemic antibiotics, generally Amoxicillin/Augmentin and antimicrobial mouthwash ( $0.2 \%$ Chlorhexidine mouthwash) in our setting.

In our study, all L3M removal under GA was given preoperative antibiotic. Prophylactic antibiotics were proven to reduce the evidence of SSI [20] [21] [22]. 
Unlike in LA procedures, patients were not routinely prescribed with preoperative antibiotic, unless it is indicated [23] [24] [25]. This may also be a contributing factor to the reduced incidence of SSI in our series. This also raises the possibility that prophylactic antibiotics (single dose) may prevent SSI.

\section{Nerve Involvement}

There was no recorded permanent paraesthesia 6 months after the MOS in our setting. Queral-Godoy et al. (2005) [26] in a retrospective study of 4995 L3M extractions, showed that most cases of inferior alveolar nerve involvement recover within 6 months, but that older patients are more likely to have incomplete recovery. Gülicher and Gerlach (2001) [27] in a prospective study of $1106 \mathrm{im}$ pacted L3M in 687 patients, showed that at 6 months postoperatively, $0.91 \%$ of patients had persistent inferior alveolar nerve involvement. Increasing age was one of the statistically significant factors identified (along with degree of root development, degree of impaction, and radiographic appearance of the relationship of the roots to the nerve). In addition to this, younger patients appear to tolerate permanent nerve involvement better than older patients.

For patients that had nerve damage during L3M removal, clinical management can follow the algorithm proposed by Robinson et al. (2004) [28]. For inferior alveolar nerve injury during the procedure, used of diathermy and haemostatic agent should be avoided and the nerves that were displaced should be reapproximated by microsurgical technique with epineural sutures which can only be done under GA. Pharmacological approach such as Pregabalin, oxcarbazepine, venlafaxine for chronic pain, and topical $5 \%$ lidocaine patches or combination of these was introduced but only provided partial relief of the symptoms. Cases of neuropathic pain can be treated as described by Renton and Yilmaz (2012) [29] which include cognitive behavior therapy, surgery, medication (Pregabalin, oxcarbazepine, venlafaxine for chronic pain), and topical $5 \%$ lidocaine patches or combination of these. For cases that were close to nerve, coronectomy was carried out, and this may be the reason that no significant difference on nerve injury was noted between LA and GA [30].

\section{Pain}

It is common to have pain for the first few days after the procedure secondary to inflammation on the surgical site. If the pain worsens, we need to rule out underlying complication such as alveolar osteitis or infection and treated accordingly. Non-steroidal anti-inflammatory drugs can be given postoperatively to patients that have no contraindication, partial opioid agonists such as tramadol as a step up drug in severe pain under LA procedure. In addition to this, tablet prednisolone $10 \mathrm{mg}$ was given for three days in tapering dose for our patients. In GA procedures, a single dose of intravenous dexamethasone $8 \mathrm{mg}$ was given at induction and a single dose of intramuscular tramadol was given post operatively. We found out that there was no significant difference (pain) between LA 
and GA procedure despite different medications prescribed for the patients.

\section{Alveolar Osteitis}

The reported incidence of dry socket in our study was 5.1\% under GA and 5.7\% under LA which correlates with the published studies that ranges from $0.3 \%$ to $26 \%$ [3] [7] [8] [9] [10]. Patients were treated with either wound irrigation with saline solution to remove food remnants, sedative dressing, mild to strong analgesic prescriptions or with combination of these, plus reassessment if the complaints persisted. There was no significant difference in incidence between LA with GA procedure in our centre.

\section{Limitations}

This study has some limitations. As the study was retrospective, the complication rate might have been underestimated. Some patients do not seek medical attention for small complications and had defaulted follow up. There was also a significant difference in antibiotic prescriptions between the two procedures. The sample size in our study was small compared to other studies.

\section{Conclusion}

In conclusion, we compared the complications arising from removal of third molar extraction in both GA and LA procedures and note that GA procedures had less surgical site infection. This may be due to the preoperative antibiotics before surgery in the group operated under GA but only a certain number of patients operated under LA. This finding also seeks to raise the question if preoperative antibiotics in all LA procedure are justified. More preventive measurements are warranted to reduce this complication. A prospective study would be ideal to further validate this audit's finding. Patients' age act as a contributing factor for the complication and should be informed of this possibility. Ideal working environment such as sterility should be emphasized for all surgical procedures. Audit can be carried out annually to ensure sterility during procedure. Patients who are medically compromised can be offered L3M removal under GA to further reduce the complication. Variation in antibiotic prescription and the correlation with SSI needs further evaluation.

\section{Acknowledgements}

The authors also wish to acknowledge and thank the Director General, Ministry of Health of Malaysia for his support and consent to conduct and publish this study. We would also like to acknowledge Dr Foo Chee Hsien, Dr Tan Wen Wu, Dr Phuan Yi Thin, Dr Lee Wei Shiu, Dr Lisa Tan Chia Sin, Dr New Hui Zhang for their help in collecting the data.

\section{Ethical Approval}

This study was approved by the hospital ethical committee for publication. 


\section{Funding}

This study was not funded by any organization.

\section{Conflicts of Interest}

We have no conflict of interest.

\section{References}

[1] Bouloux, G.F., Steed, M.B. and Perciaccante, V.J. (2007) Complications of Third Molar Surgery. Oral and Maxillofacial Surgery Clinics of North America, 19, 117-128. https://doi.org/10.1016/j.coms.2006.11.013

[2] Ziccardi, V.B. and Zuniga, J.R. (2007) Nerve Injuries after Third Molar Removal. Oral and Maxillofacial Surgery Clinics of North America, 19, 105-115.

[3] Sisk, A.L., Hammer, W.B., Shelton, D.W., et al. (1986) Complications Following Removal of Impacted Third Molars: The Role of the Experience of the Surgeon. Journal of Oral and Maxillofacial Surgery, 44, 855-859. https://doi.org/10.1016/0278-2391(86)90221-1

[4] Blondeau, F. (1994) Paraesthesia: Incidence Following the Extraction of 455 Mandibular Impacted Third Molars. Journal of the Canadian Dental Association, 60, 991-994.

[5] Valmaseda-Castellon, E., Berini-Aytes, L. and Gay-Escoda, C. (2001) Inferior Alveolar Nerve Damage after Lower Third Molar Surgical Extraction: A Prospective Study of 1117 Surgical Extractions. Oral Surgery, Oral Medicine, Oral Pathology and Oral Radiology, 92, 377-383. https://doi.org/10.1067/moe.2001.118284

[6] Queral-Godoy, E., Valmaseda-Castellon, E., Berini-Aytes, L. and Gay-Escoda, C. (2005) Inferior Alveolar Nerve Damage after Lower Third Molar Surgical Extraction: A Prospective Study of 1117 Surgical Extractions. Oral Surgery, Oral Medicine, Oral Pathology and Oral Radiology, 99, 259-264.

https://doi.org/10.1016/j.tripleo.2004.06.001

[7] Bruce, R.A., Frederickson, G.C. and Small, G.S. (1980) Age of Patients and Morbidity Associated with Mandibular Third Molar Surgery. The Journal of the American Dental Association, 101, 240-245. https://doi.org/10.14219/jada.archive.1980.0183

[8] Benediktsdóttir, I.S., Wenzel, A., Petersen, J.K., et al. (2004) Mandibular Third Molar Removal: Risk Indicators for Extended Operation Time, Postoperative Pain, and Complications. Oral Surgery, Oral Medicine, Oral Pathology and Oral Radiology, 97, 438-446. https://doi.org/10.1016/j.tripleo.2003.10.018

[9] Bloomer, C.R. (2000) Alveolar Osteitis Prevention by Immediate Placement of Medicated Packing. Oral Surgery, Oral Medicine, Oral Pathology and Oral Radiology, 90, 282-284. https://doi.org/10.1067/moe.2000.108919

[10] Chiapasco, M., De Cicco, L. and Marrone, G. (1993) Side Effects and Complications Associated with Third Molar Surgery. Oral Surgery, Oral Medicine, Oral Pathology and Oral Radiology, 76, 412-420.

[11] Luchesi, L. and Kwok, J. (2008) Long Term Antibiotics and Calcitonin in the Treatment of Chronic Osteomyelitis of the Mandible: Case Report. British Journal of Oral and Maxillofacial Surgery, 46, 400-402. https://doi.org/10.1016/j.bjoms.2007.09.007

[12] Libersa, P., Roze, D., Cachart, T. and Libersa, J.C. (2002) Immediate and Late Mandibular Fractures after Third Molar Removal. Journal of Oral and Maxillofacial 
Surgery, 60, 163-166. https://doi.org/10.1053/joms.2002.29811

[13] Manani, G.,Facco, E., Fabero, L., et al. (2011) Comparison by Means of Bispectral Index Score, between Anxiolysis Induced by Diazepam and Sedation Induced by Midazolam. Minerva Stomatologica, 60, 365-381.

[14] Low, L., Audimulam, H., Lim, H., Selvaraju, K. and Balasundram, S. (2017) Steroids in Maxillofacial Space Infection: A Retrospective Cohort Study. Open Journal of Stomatology, 7, 397-407.

[15] Freudlsperger, C., Deiss, T., Bodem, J., et al. (2012) Influence of Lower Third Molar Anatomic Position on Postoperative Inflammatory Complications. Journal of Oral and Maxillofacial Surgery, 70, 1280-1285.

https://doi.org/10.1016/j.joms.2011.12.014

[16] Pourmand, P.P., Sigron, G.R., Mache, B., et al. (2014) The Most Common Complications after Wisdom-Tooth Removal: Part A Retrospective Study of 1562 Cases in the Maxilla. Swiss Dental Journal, 124, 57-61.

[17] Clauser, B., Barone, R., Briccoli, L., et al. (2009) Complications in Surgical Removal of Mandibular Third Molars. Minerva Stomatologica, 58, 359.

[18] Umscheid, C.A., Mitchell, M.D., Doshi, J.A., Agarwal, R., Williams, K. and Brennan, P.J. (2011) Estimating the Proportion of Healthcare-Associated Infections That Are Reasonably Preventable and the Related Mortality and Costs. Infection Control \& Hospital Epidemiology, 32, 101-114. https://doi.org/10.1086/657912

[19] Damani, N. and Emmerson, A. (2003) Manual of Infection Control Procedures. 2nd Edition, Greenwich Medical Media.

[20] Andersen, B., Kallehave, F. and Andersen, H. (2005) Antibiotics versus Placebo for Prevention of Postoperative Infection after Appendicectomy. Cochrane Database of Systematic Reviews, 3, CD001439. https://doi.org/10.1002/14651858.CD001439.pub2

[21] Halpern, L.R. and Dodson, T.B. (2007) Does Prophylactic Administration of Systemic Antibiotics Prevent Postoperative Inflammatory Complications after Third Molar Surgery. Journal of Oral and Maxillofacial Surgery, 65, 177-185. https://doi.org/10.1016/j.joms.2006.10.016

[22] Lodi, G., Figini, L., Sardella, A., et al. (2012) Antibiotics to Prevent Complications Following Tooth Extractions. Cochrane Database of Systematic Reviews, 11, CD003811. https://doi.org/10.1002/14651858.CD003811.pub2

[23] Prajapati, A., Prajapati, A. and Sathaye, S. (2016) Benefits of Not Prescribing Prophylactic Antibiotics after Third Molar Surgery. Journal of Maxillofacial and Oral Surgery, 15, 217-220. https://doi.org/10.1007/s12663-015-0814-1

[24] Rohit, S. and Praveen Reddy, B. (2014) Efficacy of Postoperative Prophylactic Antibiotic Therapy in Third Molar Surgery. Journal of Clinical and Diagnostic Research, 8, ZC14-ZC16.

[25] Bortoluzzi, M.C., Capella, D.L., Barbieri, T., et al. (2013) A Single Dose of Amoxicillin and Dexamethasone for Prevention of Postoperative Complications in Third Molar Surgery; a Randomized, double-blind, Placebo Controlled Clinical Trial. Journal of Clinical Medicine Research, 5, 26-33.

[26] Queral-Godoy, E., Valmaseda-Castellón, E., Berini-Aytés, L., et al. (2005) Incidence and Evolution of Inferior Alveolar Nerve Lesions Following Lower Third Molar Extraction. Oral Surgery, Oral Medicine, Oral Pathology, Oral Radiology, and Endodontology, 99, 259. https://doi.org/10.1016/j.tripleo.2004.06.001

[27] Gülicher, D. and Gerlach, K.L. (2001) Sensory Impairment of the Lingual and Infe- 
rior Alveolar Nerves Following Removal of Impacted Mandibular Third Molars. International Journal of Oral and Maxillofacial Surgery, 30, 306.

https://doi.org/10.1054/ijom.2001.0057

[28] Robinson, P.P., Loescher, A.R., Yates, J.M., et al. (2004) Current Management of Damage to the Inferior Alveolar and Lingual Nerves as a Result of Removal of Third Molars. British Journal of Oral and Maxillofacial Surgery, 42, 285-292. https://doi.org/10.1016/j.bjoms.2004.02.024

[29] Renton, T. and Yilmaz, Z. (2012) Managing Iatrogenic Trigeminal Nerve Injury: A Case Series and Review of the Literature. International Journal of Oral and Maxillofacial Surgery, 41, 629-637. https://doi.org/10.1016/j.ijom.2011.11.002

[30] O’Riordan, B.C. (2004) Coronectomy (Intentional Partial Odontectomy of Lower Third Molars). Oral Surgery, Oral Medicine, Oral Pathology, Oral Radiology, and Endodontology, 98, 274-280. https://doi.org/10.1016/j.tripleo.2003.12.040 